\title{
OTR4 - ANÁliSE E CONTROLE DE RISCOS ASSOCIADOS AO SISTEMA EMBALAGEM DE PRODUTOS FARMACÊUTICOS
}

\section{$\underline{\text { Gisele Corrêa Miranda }^{1}}$}

1. Bio-Manguinhos, Fundação Oswaldo Cruz, Rio de Janeiro, Brasil.

Objetivos: O objetivo desse trabalho é entender os perigos, riscos, e impacto potencial referentes ao processo de desenvolvimento de embalagem de produtos farmacêuticos, com enfoque ampliado em todos os processos relacionados a essa atividade, que envolvem desde o projeto estrutural e gráfico, passando especificação e compra dos materiais, pelo processamento do produto, armazenagem, distribuição e uso pelo consumidor, o que pode ser considerado como Sistema Embalagem, e propor mecanismos de atuação e controle para redução ou eliminação desses perigos.

Métodos: Métodos tradicionais na indústria de Análise de Perigos e Pontos Críticos de Controle (APPCC ou HACCP em inglês) e a Análise de Efeitos e Modos de Falha (FMEA) podem ser utilizados para a análise e controle de riscos no Sistema embalagem. Esses métodos indicam como ponto de partida a identificação dos perigos, a avaliação da sua probabilidade de ocorrer e impacto dos danos à saúde pública em termos de extensão e gravidade. Para adaptação desses métodos de análise de risco para o Sistema Embalagem de produtos farmacêuticos, é necessário primeiro entender e registrar quais são as funções primárias (contenção, proteção e viabilizadora do transporte) e secundárias (econômica, tecnológica, de marketing, de comunicação, conceitual, sociocultural e de meio-ambiente) das embalagens. Dessa forma são considerados perigos os fatores que podem afetar a qualquer uma dessas funções da embalagem.

Resultados: Perigos de quatro naturezas são encontrados no processo de desenvolvimento de embalagem de produtos farmacêuticos, estéreis e termo sensíveis, sendo eles: (1) perigos físicos (vazamento de produto, problemas na estanqueidade da embalagem primária, presença de substancias estranhas, dificuldade ergonômica associada ao armazenamento, transporte, manipulação ou uso, inadequação aos equipamentos e processos de embalagem, volume e dimensões incompatíveis com os equipamentos refrigerados ou que dificultem a armazenagem e transporte); (2) perigos químicos (contaminação química na embalagem primária, material de embalagem reage 
com o produto, embalagem não garante a estabilidade química do produto); (3) perigos biológicos (material de embalagem contaminado, contaminação no processo de embalagem, embalagem que não garante esterilidade durante a vida útil do produto, embalagem que permite proliferação de microrganismos ); e (4) perigos cognitivos (informação incorreta ou contraditória indicada na embalagem; inadequação à legislação atual, confusão na identificação do produto, falha de comunicação sobre condições de transporte e estocagem do produto).

Conclusão: Existem muitos perigos relacionados ao desenvolvimento de embalagem, que podem afetar a qualidade de produtos farmacêuticos. O uso de ferramentas de análise de riscos tradicionais na indústria, tais como a Análise de Perigos e Pontos Críticos de Controle (APPCC) e a Análise Efeitos e Modos de Falha (FMEA), associadas ao Sistema Embalagem, podem ser efetivas na análise e controle de perigos e riscos no desenvolvimento das embalagens e definição de processos de embalagem desses produtos farmacêuticos. 